\title{
The use of narcotic analgesics in terminal illness
}

\author{
Robert G Twycross St Christopher's Hospice, London
}

To answer some of the questions surrounding the medicinal use of narcotic analgesics in advanced cancer, a group of 500 patients admitted to St Christopher's Hospice was reviewed. To achieve and maintain pain relief many of the patients received diamorphine (heroin) regularly every four hours. Almost all the patients received a phenothiazine concurrently; other drugs were prescribed when indicated. It was concluded that: I) Although most patients receive parenteral diamorphine during the last 12 to 24 hours, the majority can be maintained on oral medication until this time. 2) There is no single optimal dose of diamorphine. 3)

Psychological dependence does not occur. 4) Physical dependence may develop but does not prevent the downward adjustment of the dose of diamorphine when considered clinically feasible. 5) Tolerance is not a practical problem. 6) The prescription of diamorphine does not, by itself, lead to impairment of mental faculties.

Also discussed are: I) the psychobiological nature of pain; 2) the rational use of analgesics; 3) the need for further research; 4) the importance of the doctor's attitude.

Attention has recently been drawn to a form of iatrogenic drug abuse - the failure to treat patients in severe pain with adequate doses of narcotic analgesics (Marks and Sachar, 1973), a matter of too little being given too late or not at all. From this and other sources it appears that, because of fears of addiction, the rapid escalation of dose, and the impairment of mental faculties, doctors generally are reluctant to prescribe narcotic analgesics even in patients with advanced cancer. This reluctance is illustrated in the following quotation:

'What about the inoperable cancer patient who may not die for months or a year, and yet who is suffering agonies from chronic pain? This type of patient may fail to get relief from anything but the most potent narcotics. Is a doctor then justified in prescribing such drugs when he knows full well he will be sentencing his patient to a kind of living death?' (Bunyard, 1971).

It might seem to the casual observer that the dying cancer patient has only two options: either an agonising death or a 'kind of living death' in which pain is relieved only at the expense of rational existence. Either way, the life that remains is seen as a parody of what life is meant to be. He hears of patients calling upon the Almighty to end their. suffering, of the less religious contemplating $\overrightarrow{\vec{\omega}}$ suicide, and concludes that the only compassionate $\stackrel{s}{\rightarrow}$ way out of the impasse is 'euthanasia.' But is this so? In order to answer this question, it was decided to review the use of narcotic analgesics at $\mathrm{St}$. Christopher's Hospice where diamorphine (heroin) $\overrightarrow{0}$ is the strong analgesic of choice.

More than five hundred patients with advanced cancer are admitted to the Hospice each year. $\rightarrow$ About 80 per cent of these receive diamorphine at some time during their time at the Hospice. $\overrightarrow{\vec{\theta}}$ Usually it is prescribed for severe pain; occasionally, for distressing cough or dyspnoea due to the malignant process, or for general discomfort when other measures have failed. Fifteen per cent of the patients receive diamorphine either predominantly or entirely by injection, the rest by mouth in an elixir containing both diamorphine and cocaine. It $\stackrel{\mathbb{Q}}{\Omega}$ is administered regularly every four hours in $\overrightarrow{\overrightarrow{0}}$ order to achieve and maintain pain relief. The 3 initial dose of diamorphine is usually 2.5 - Io $\mathrm{mg}$; this is adjusted as necessary until effective analgesia is obtained. The dose of cocaine is not altered. With the aid of a night sedative many patients do not $\overparen{\curvearrowright}$ require a dose in the middle of the night though, if necessary, the patient is wakened for further medication rather than leaving him to wake up $\delta$ later complaining of pain. Ultimately, most patients are transferred to parenterally administered dia- $\frac{\mathrm{O}}{9}$ morphine for the last 12 to 24 hours of life on $D$ account of increasing debility.

Virtually all patients receiving diamorphine are N also prescribed a phenothiazine, for example, prochlorperazine, promazine or chlorpromazine, $\mathbb{N}$ primarily to control or prevent nausea and vomiting but also for sedation and analgesia potentiation. Other drugs, such as glucocorticosteroids, tran-o quilizers, and antidepressants, are also prescribed $\Phi$ when indicated.

\section{Review of 500 patients}

The notes of 500 patients admitted consecutively $\frac{\mathbb{D}}{\mathbb{Q}}$ with advanced cancer were reviewed retrospectively. $\bar{O}$ Two hundred and eighty-two $(56 \%)$ were women, $218(44 \%)$ were men. Their median age was 63 응 years and median survival after admission was $16=$ 


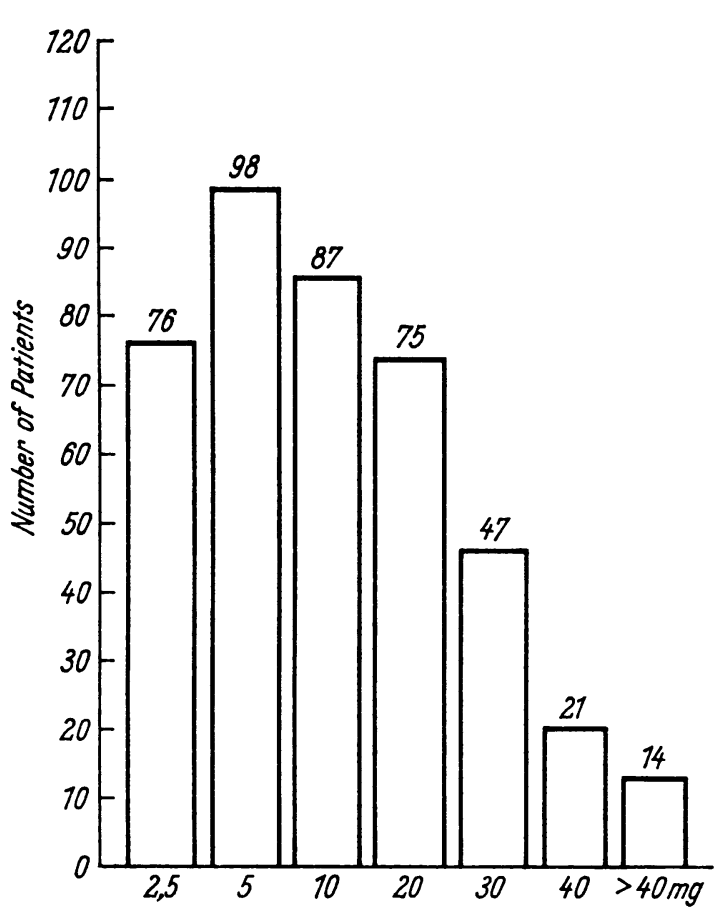

FIG I Histogram of maximum four-hourly doses

days. Four hundred and eighteen $(84 \%)$ received diamorphine for varying lengths of time. A histogram was constructed of the maximum four-hourly doses (fig I). Over $60 \%$ of these patients were maintained on a dose of $10 \mathrm{mg}$ or less and only $8 \%$ required more than $30 \mathrm{mg} / \mathrm{dose}$. All the patients represented in the more than $40 \mathrm{mg} /$ dose column received such doses by injection - II patients requiring 50 or $60 \mathrm{mg}$ and three $90 \mathrm{mg}-$ and some six to Io patients represented in the other columns also received their maximum dose by injection.

In order to examine the rate of increase in dose, patients were grouped according to survival, excluding the 213 who died within a week of commencing treatment (table I). The median final daily dose for each group was then determined, and, in order to correct for time, divided by the group median duration of treatment. The resulting dose/time coefficients demonstrate clearly that the rate at which the dose increases becomes progressively less the longer the duration of treatment. Further, examination of the individual dose-againsttime graphs prepared for the 108 patients who received diamorphine for at least four weeks indicated that there were four general patterns of diamorphine requirement. These were classified as: step-plateau-step-plateau, plateau, undulating, and crescendo-diminuendo. Their incidence was approximately $40,40,15$, and 5 per cent respectively.

Forty-six patients were discharged for varying lengths of time (days out and weekends not included) and, of these, 22 were on diamorphine when discharged (table II). They were all alert and mobile, though one or two of the elderly ones used a walking frame.

TABLE II Diamorphine requirements in 22 discharged patients

\begin{tabular}{|c|c|}
\hline $\begin{array}{l}\text { Daily Dose of Diamorphine } \\
(m g)\end{array}$ & Number of Patients \\
\hline 12.5 & $5(4)^{1}$ \\
\hline 25 & I (2) \\
\hline 50 & $4(2)$ \\
\hline 100 & $8(4)$ \\
\hline \multirow[t]{2}{*}{150} & 4 (10) \\
\hline & 22 \\
\hline
\end{tabular}

${ }^{1}$ The figures in parentheses refer to the number of patients ultimately given the dose while being cared for at home.

\section{Case histories}

The case histories of 13 patients who survived for

TABLE I Assessment of the rate of increase in dose of diamorphine in 205 patients receiving regular diamorphine for one week or more

\begin{tabular}{lccccc}
\hline & \multicolumn{7}{l}{ Number of Complete Weeks } \\
\cline { 2 - 6 } & \multicolumn{1}{l}{ I } & $2-3$ & $4-7$ & $8-15$ & $\geq 16$ \\
\hline Number of patients & 58 & 39 & 53 & 34 & 21 \\
Median final daily dose (mg) & 50 & 60 & 95 & 125 & 135 \\
Median duration of treatment (weeks) & 1.5 & 3 & 6 & 12 & 24 \\
Dose/time $^{1}$ & 33 & 20 & 16 & 10 & 6 \\
\hline
\end{tabular}

${ }^{1}$ The figures in the bottom row are obtained by dividing the group median final daily dose in $\mathrm{mg}$ by the group median duration of treatment in weeks. 
TABLE III Summarized data relating to five patients alive 24 weeks after starting treatment with diamorphine

\begin{tabular}{|c|c|c|c|c|c|c|}
\hline $\begin{array}{l}\text { Case } \\
\text { No }\end{array}$ & Sex & Age & $\begin{array}{l}\text { Primary } \\
\text { Site of } \\
\text { Carcinoma }\end{array}$ & $\begin{array}{l}\text { Duration of } \\
\text { Treatment } \\
\text { with } \\
\text { Diamorphine } \\
\text { (weeks) }\end{array}$ & $\begin{array}{l}\text { Initial } \\
\text { Clinical Condition }\end{array}$ & Subsequent Course of Events \\
\hline $\mathbf{I}$ & $\mathrm{F}$ & 64 & Breast & 99 & $\begin{array}{l}\text { Bedfast, nauseated } \\
\text { and anorexic, weight } \\
\text { loss, severe pain in back } \\
\text { and right leg }\end{array}$ & $\begin{array}{l}\text { Nausea and pain gradually controlled, } \\
\text { appetite returned to normal. Fully } \\
\text { mobile after two months. Subsequently } \\
\text { discharged but readmitted several times on } \\
\text { account of pain and/or depression. In- } \\
\text { patient for last Io weeks: mood variable } \\
\text { during this time. Diamorphine administered } \\
\text { parenterally for last five weeks due to a } \\
\text { recurrence of pain. }\end{array}$ \\
\hline 3 & $\mathbf{F}$ & 62 & Breast & 50 & $\begin{array}{l}\text { In pain, nausea, some } \\
\text { vomiting. Able to walk } \\
\text { with crutches }\end{array}$ & $\begin{array}{l}\text { Became fully mobile, despite pain from } \\
\text { fresh metastatic activity. Eventually able } \\
\text { to go home for over three months. Finally } \\
\text { readmitted with pneumonia and died } \\
\text { within hours. }\end{array}$ \\
\hline 8 & M & 70 & Prostate & 28 & $\begin{array}{l}\text { Depressed by constant } \\
\text { pain in thoracic spine, } \\
\text { pelvis, and other bones. } \\
\text { Complained of insomnia, } \\
\text { anorexia, and weight } \\
\text { loss. Able to walk a } \\
\text { little }\end{array}$ & $\begin{array}{l}\text { Became free of pain, fully mobile, ate and } \\
\text { slept normally. Felt exceptionally well. } \\
\text { Discharged after seven weeks. At home for } \\
4 \frac{1}{2} \text { months, gradually weakening latterly. } \\
\text { Readmitted and died after one week. }\end{array}$ \\
\hline I2 & $\mathbf{F}$ & 56 & Breast & 24 & $\begin{array}{l}\text { Bedfast; in severe } \\
\text { pain in both thighs, } \\
\text { hips, and left pelvis. } \\
\text { Nausea, anorexia, } \\
\text { Paranoid and depressed }\end{array}$ & $\begin{array}{l}\text { Fully mobile and pain-free. Psychiatric } \\
\text { state required constant surveillance. } \\
\text { Diamorphine eventually discontinued and } \\
\text { patient discharged for five months. } \\
\text { Terminal phase probably precipitated by } \\
\text { cessation of prednisone; fairly rapid } \\
\text { deterioration over several weeks with } \\
\text { evidence of renewed secondary activity. }\end{array}$ \\
\hline 13 & $\mathbf{F}$ & 16 & $\begin{array}{l}\text { Osteo- } \\
\text { sarcoma }\end{array}$ & 15 & $\begin{array}{l}\text { Severe pain left groin } \\
\text { and calf. Discharging } \\
\text { biopsy wound. Marked } \\
\text { anorexia and nausea. } \\
\text { Incontinent of urine, } \\
\text { very frightened, } \\
\text { withdrawn }\end{array}$ & $\begin{array}{l}\text { Required increasing doses of diamorphine } \\
\text { as mobilized. Eventually tailed off in } \\
\text { view of remission. A limp due to left } \\
\text { leg shortening only residium. } \\
\text { Alive and well five years later. }\end{array}$ \\
\hline
\end{tabular}

six months or more after commencing treatment with diamorphine have been reported elsewhere (Twycross, 1974). Details of five are, however, included (table III and fig 2).

In case $I$ the dose of diamorphine undulated. Several of the upward adjustments in the dose of diamorphine were for pain associated with different metastatic lesions. This fact, coupled with the subsequent decrease in dose, suggests that the increases in diamorphine were not due to tolerance but because of increased pain.

In case 3 , where the dose chart shows three elevations, the first and third relate to clearly defined episodes. In both, new pain caused by fresh metastatic activity precipitated the increased $\stackrel{N}{\circ}$ requirement. In the second elevation, the recurrence $N_{\omega}$ of previous pain led to the increase. At first sight $\sigma^{2}$ tolerance to diamorphine might be suspected.c However, the ability to make a fourfold reduction in dose some three weeks later suggests that this $\stackrel{\oplus}{+}$ elevation also resulted from an acute episode $\square$ relating to a bony metastasis. The final reduction, made by the patient's general practitioner, led to $\stackrel{\mathbb{D}}{\Omega}$ recurrence of intermittent discomfort demonstrating $\mathbb{D}$ that the patient still required analgesia at this stage.

Case 8 is notable in that the patient required diamorphine by injection during the early part of $O$ treatment due to poor control of pain on the oral 

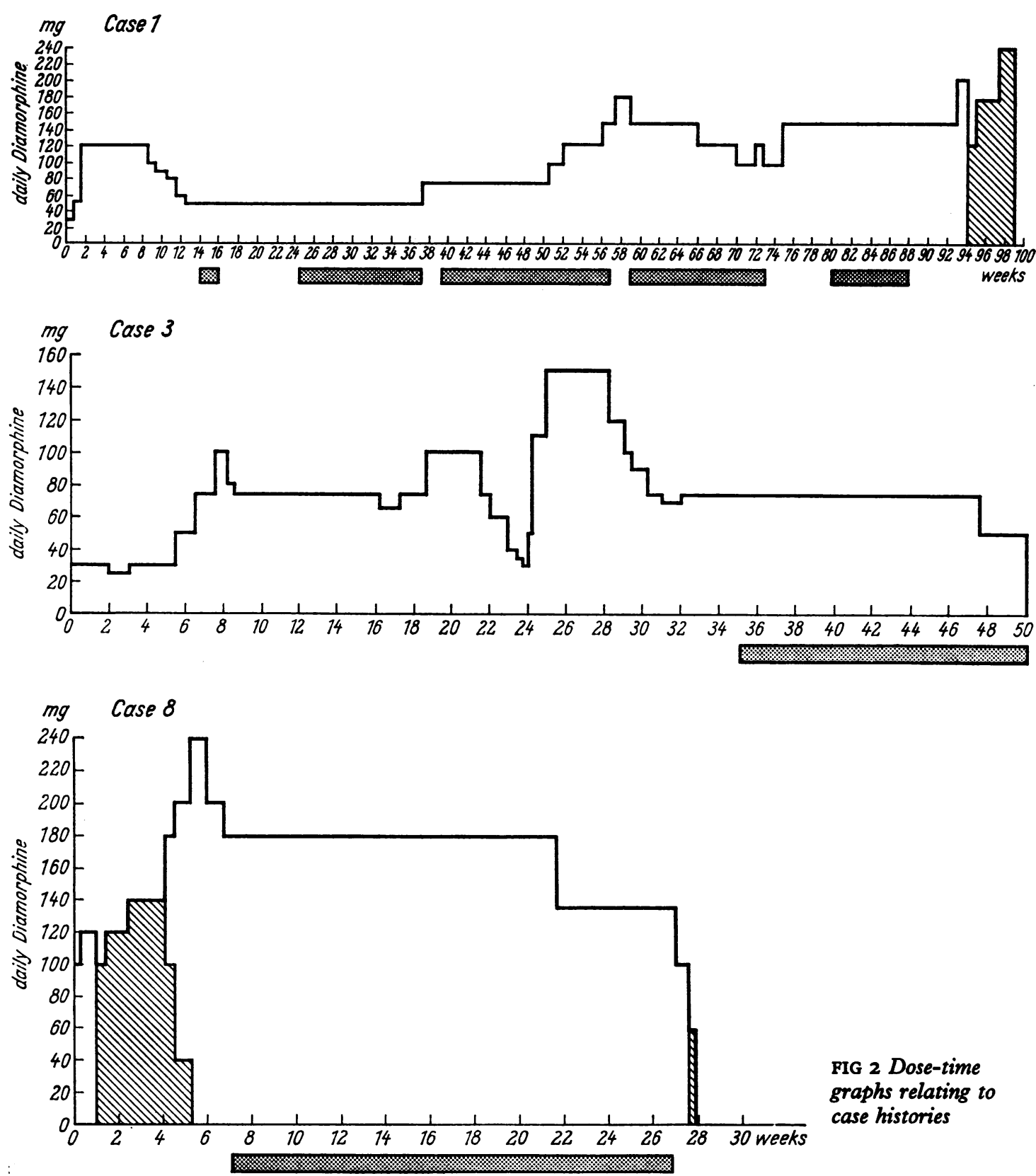

FIG 2 Dose-time graphs relating to case histories

preparation. If we accept that, by injection, diamorphine is approximately twice as potent, this patient was receiving the equivalent of diamorphine $280 \mathrm{mg} /$ day by mouth after three weeks. Subsequently he reverted to oral therapy and it was possible, later, to reduce the dose still further. The pain, once controlled, did not recur apart from one or two isolated occasions. In cases 12 and 13 it was possible to curtail treatment with diamorphine completely, the reduction in dose being linked to reduction in pain. Neither patient experienced symptoms attributable to withdrawal of diamorphine.

\section{Discussion}

ORAL MEDICATION

Eighty-five per cent of the patients were maintained on oral therapy until death or until the last 12 to 24 hours before death, when increasing debility made oral administration difficult if not impossible. 


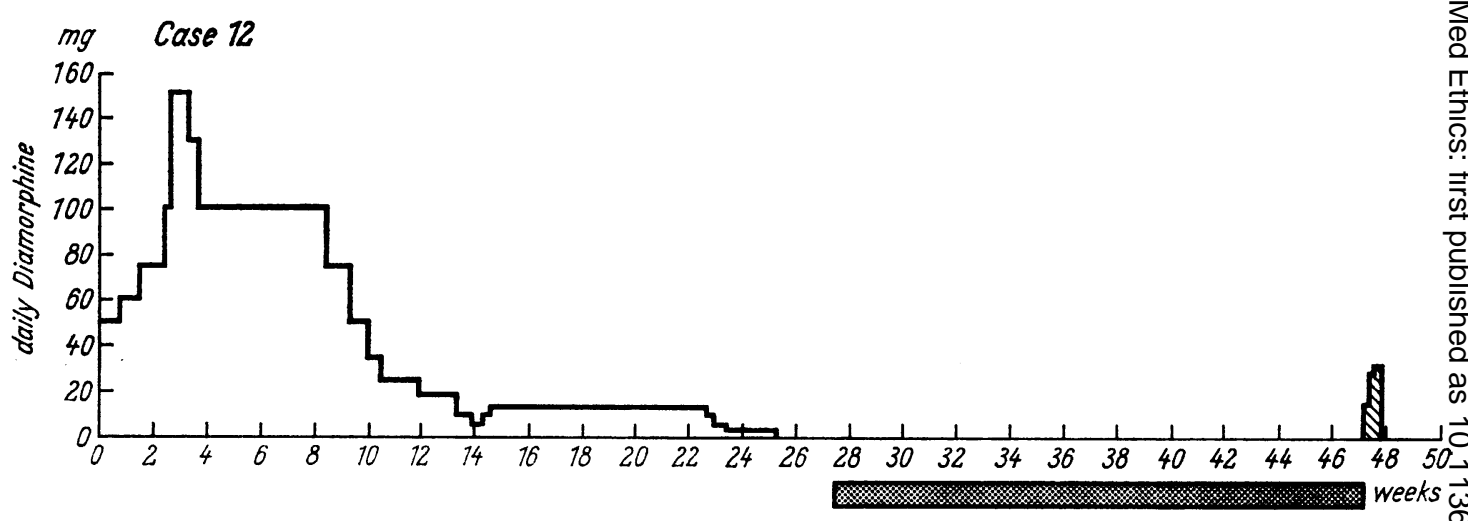

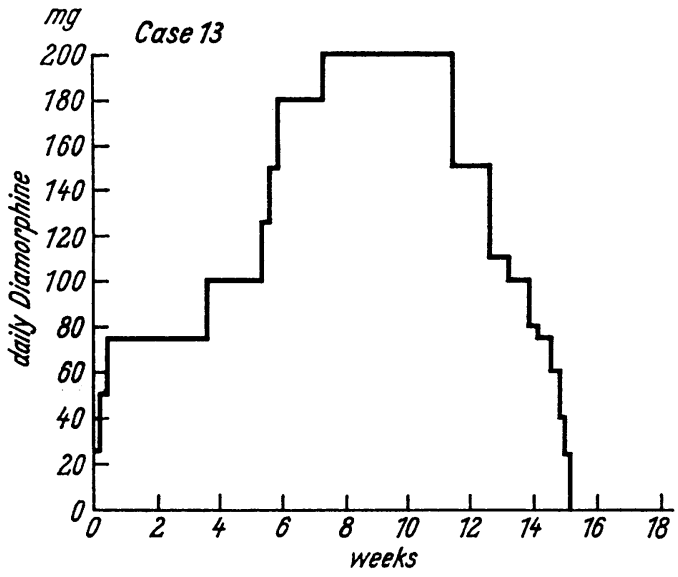

The main reason for parenteral administration at an early stage was unrelieved nausea and vomiting.

Although a range of synthetic narcotics is available in tablet and suppository form, the prescription of morphine or diamorphine is often still equated with injections. This review demonstrates that this is a fallacy as far as diamorphine is concerned, and unpublished data (Twycross) indicate that solutions of morphine are also effective. Recently we have started using oral doses of 60 and $90 \mathrm{mg}$ of diamorphine rather than change to injections should pain control become inadequate on $40 \mathrm{mg}$.

THE OPTIMAL DOSE

Twenty years ago the optimal dose of a drug was defined by Lasagna and Beecher (1954) as that which provides the desired therapeutic effects with a minimum of undesirable side effects. A study of the dose-response curve for morphine administered intramuscularly in postoperative patients led them to conclude that the optimal dose was $10 \mathrm{mg}$ per 70 $\mathrm{kg}$ body weight. Although one cannot disagree with their definition, it is incorrect to equate the dose above which the dose-response curve begins to flatten with 'optimal dose'. The optimal doses of
Oral Diamorphine Hydrochloride

Parenteral Diamorphine Hydrochloride

Time at home

FIG 2 Dose-time graphs relating to case histories

(Figures $I$ and 2 are reproduced by kind permission of Messrs, Urban and Schwartzenberg, Munich.)

diamorphine in the patients reviewed ranged from. as little as $2.5 \mathrm{mg}$ by mouth to $90 \mathrm{mg}$ by injection, the latter being equivalent to $200 \mathrm{mg}$ of intra- $\mathbb{\Phi}$ muscular morphine.

\section{ADDICTION}

Although the term 'drug addiction' has been replaced officially by 'drug dependence', unofficially it윽 continues to be used. Drug dependence is currently defined as:

'A state, psychic and sometimes also physical, N resulting from the interaction between a living $N$ organism and a drug, characterised by behavioural and other responses that always include a compul- $\sigma$ sion to take the drug on a continuous or periodic basis in order to experience its psychic effects, and? sometimes to avoid the discomfort of its absence. Tolerance may or may not be present.' (World Health Organisation, 1969).

This is a broader definition than that of $1964 \stackrel{\mathbb{2}}{\circ}$ which emphasized the need for both tolerance and $\bar{\alpha}_{2}$ an early development of physical dependence ino addition to strong psychological dependence (World Health Organisation, 1964). The term 'drugo dependence' now more closely approximates to the 
popular conception of addiction - a compulsion or overpowering drive to take the drug in order to experience its psychological effects. On this definition none of the patients reviewed became addicted. Occasionally a patient has been admitted to the Hospice who appears to be addicted, demanding 'an injection' every two or three hours. Such a patient typically has a long history of poor control of pain and will, for several weeks, have been receiving fairly regular ('four-hourly-prn') but inadequate injections of one or more narcotic analgesics. Given time, it is usually possible to control the pain adequately, prevent clock watching and the demanding behaviour, and, sometimes, transfer the patient on to an oral preparation. But even here, can it be said that the patient is truly addicted? Is he craving the narcotic in order to experience its psychological effects? Or is he craving relief from pain, in part if not in full, for at least an hour or two?

\section{PHYSICAL DEPENDENCE}

It is possible, but by no means certain, that many of the 205 patients who received diamorphine for more than one week became physically dependent on it. Eddy and his associates have reviewed cancer patients maintained on subcutaneous morphine, oxymorphone, and anileridine (Eddy, Lee, and Harris, 1959). They tested for physical dependence by injecting nalorphine hydrochloride $\mathrm{I}$ mg subcutaneously at fortnightly intervals. They were able to show that over half the patients had developed physical dependence by the end of the second week of treatment and that it was unusual for a patient not to be physically dependent by the end of the fourth week. All the patients were receiving morphine by injection, whereas according to Lee (I942), when administered by mouth dependence develops less rapidly and, possibly, to a lesser degree. Even so, whether or not physical dependence develops, it does not prevent the gradual downward adjustment of dose nor the complete curtailment of treatment when this becomes clinically feasible.

\section{TOLERANCE}

The data in this review, especially those relating to patients who survived for 24 weeks or more after commencing treatment with diamorphine, support the hypothesis that increases in dose are caused more by increased pain than by tolerance. It is, of course, possible to induce marked tolerance by needlessly increasing the dose (Fraser, Isbell, and Van Horn, 1957). However, there is certainly no support for the statement that, due to tolerance, morphine is no longer effective after three months of continuous use (Milton, 1972). In practice, when diamorphine is used as at St Christopher's Hospice regularly, prophylactically and as part of a pro- gramme of total care, tolerance, if it occurs, is not a practical problem.

\section{IMPAIRMENT OF MENTAL FACULTIES}

As already mentioned, it has been suggested that the administration of a potent narcotic analgesic to a patient with inoperable cancer is like sentencing him 'to a kind of living death' (Bunyard, 197I). Others speak of 'detachment from reality' or imply that patients receiving morphine or diamorphine can do little more than lie 'drugged' in bed. It appears, however, in the present series of patients that an oral daily dose of $150 \mathrm{mg}(30 \mathrm{mg} \times 5)$ is not incompatible with normal activity (table II). This is borne out by one's own experience of treating several hundred patients with diamorphine which has demonstrated that there is no significant correlation between the dose administered and mobility (Twycross, unpublished observations). 'Detachment from reality' - if it occurs - and drowsiness would appear to be related more to advanced physical debility than to diamorphine per se.

\section{ADJUVANT MEDICATION}

In addition to the concomitant use of a phenothiazine, a quarter of the patients were prescribed either a tricyclic antidepressant or a benzodiazepine tranquillizer. Generally speaking, the latter were used for short periods to help patients at times of particular stress or anxiety while the former were used for longer periods in many of the more long-term survivors. Glucocorticosteroids were prescribed for about half the patients for a variety of reasons (Drug and Therapeutics Bulletin, 1974). Some patients required additional antiemetics, such as cyclizine or metoclopramide. The majority needed laxatives either regularly or from time to time. The use of a wide variety of pharmacological agents, although not without danger, may well have reduced the amount of diamorphine required to achieve satisfactory analgesia.

\section{The nature of pain}

Pain is a psychobiological phenomenon; that is, apart from its anatomical and physiological components, it has a psychological aspect. Failure to appreciate this can limit the degree of relief from pain obtainable with narcotic analgesics (Twycross, 1972). Further, continuous (chronic) pain differs from acute pain in that it is a situation rather than an event, impossible to predict when it will end, usually gets worse rather than better, appears to be entirely meaningless and frequently expands to occupy the patient's whole attention, isolating him from the world around. Consequently there is a greater likelihood of a negative (pain-potentiating) psychological component in chronic pain than in acute pain. Depression, anxiety, fear, mental 
isolation, other unrelieved symptoms, and pain itself will all tend to exacerbate the total experience of pain. To relieve the pain all these factors must be considered.

Pain due to advancing cancer is usually continuous even if variable in intensity. Accordingly, treatment should also be continuous, that is, prophylactic or preventative rather than pro re nata or 'as required'. Pain is a potent 'antanalgesic' and to allow the pain to re-emerge before administering the next dose not only causes unnecessary suffering but encourages clinical tolerance. In the light of these comments it should be possible to devise a more rational use of analgesics in terminal cancer.

The aim is to keep the patient both free of pain and fully alert. The method is as follows:

I Analgesics should be given regularly and prophylactically: 'prn' is both irrational and inhumane.

2 The right dose is that which gives relief for a reasonable period of time: a four-hourly interval should generally be regarded as the norm between administrations.

3 Non-narcotic analgesics should be tried initially.

4 If ineffective - transfer to a stronger preparation.

5 Establish a simple, practical analgesic 'league table' (table IV).

\section{TABLE IV Analgesic league table1, 2}

I Morphine/diamorphine/levorphanol/ methadone

2 Intermediate strength synthetics (eg, hydromorphone, dipipanone)

3 Codeine/propoxyphene \pm 4

Increasing potency

4 Aspirin/paracetamol

${ }^{1}$ This is not intended to be exhaustive.

${ }^{2}$ Petbidine and pentazocine have been omitted as both are unreliable by mouth and relatively short-acting by injection.

6 Adjuvant medication is, in practice, the rule rather than the exception.

7 Use oral medication whenever possible: it is easier to administer, enables the patient to be more independent, and facilitates domiciliary care.

8 There is more to analgesia than analgesics. Some pain responds better to other forms of treatment, eg radiotherapy, cytotoxic drugs, nerve blocks, alone or in combination with analgesics.

The value of diversional activity should not be forgotten. It ranges from back rubs to occupational therapy, talking books, access to radio and television someone to talk to, and dayroom activities. Pain feels worse when it occupies the entire life fieldF. Diversional activity does much more than just 'pass' the time'; it also diminishes the pain. Both 'atten tion' and 'consciousness' are essential to the perception of pain. We can reduce one or other, bu民 the reduction of 'attention' can often be surprisingl effective.

\section{Diamorphine in perspective}

It is clear that diamorphine cannot be regarded as a panacea for terminal cancer. For instance, more than half the patients who survived 24 weeks afte? commencing treatment with diamorphine require $\bar{B}$ tricyclic antidepressants. Unless it, or any othet analgesic, is used within the context of total patient care, the results will be far from satisfactory. $\vec{\circ}$

At St Christopher's, a comparative study of dia음 morphine and morphine has been completed and, currently, the cocaine in the standard elixir is being evaluated. It is planned to compare diamorphine with other narcotic analgesics and, eventually, to assess the adjunctive use of phenothiazines.

In addition, steps are being taken to elucidate the complex and complicating role of glucocortico-o steroids. In case I, for example, it is likely that thes patient was hypercalcaemic when admitted: sheo improved steadily once prednisone was prescribed.\% Hypercalcaemia is known to precipitate or exacer bate pain in malignant disease and its correction to $\overrightarrow{\overrightarrow{0}}$ cause relief (Galasko and Burn, 197I). It is possible 3 that alteration of the biochemical milieu in other? ways may alter the pain threshold and thus patient's narcotic requirement.

\section{Pain in perspective}

Published data suggest that as many as $50 \%$ of all terminal cancer patients have no pain at all or negligible discomfort at most. Forty per cent do, however, experience severe pain and the remaining $10 \%$ suffer pain of a less intense nature (Turnbull, 1954; Aitken-Swan, 1959). Further, it is theoretically, possible to relieve pain in every case. Success $N$ depends on the doctor having an adequate concept of the nature of pain, knowledge concerning the ${ }^{\omega}$ correct use of analgesics and links with specialist colleagues so that assistance can be obtained inf 'problem cases'. Equally important is the doctor's attitude to the dying patient:

'As the doctor-patient relationship improved, many doctors found they could reduce the drugs. $\cap$ As the true diagnosis of the patient's pain became $\frac{}{2}$ clear and the patient was helped to deal with theo pain of dying, there was less need for sedatives tranquillizers, and analgesics. This almost certainlyo reflected the doctor's own feelings. Once he was 
able to deal with his own pain of the patient dying ... the need for drugs became less. In many instances there was, at the same time, an increased demand on the doctor's time. A number of well documented cases bear this out' (Harte, 1975).

It seems likely that many commonly accepted facts concerning the long-term use of narcotics are probably little more than folklore, handed down from one medical generation to the next. It is the author's hope that the data contained in this article will go some way to raising the subject from the realm of folklore into that of scientific fact.

The author wishes to thank Miss Elizabeth Spinks for collating much of the provisional data. He is in receipt of a research fellowship from the Sir Halley Stewart Trust. The work was supported by a grant from the Department of Health and Social Security, London.

\section{References}

Aitken-Swan, J (1959). Nursing the late cancer patient at home. Practitioner, 183, 64-69.

Bunyard, P (197I). Intractable pain - How treatable is it? World Medicine, I December, 17-25.

Drug and Therapeutics Bulletin (1974). Corticosteroids in terminal cancer, 12, 63-64.

Eddy, N B, Lee, L E, and Harris, C A (1959). The rate of development of physical dependence and tolerance to analgesic drugs in patients with chronic pain. I. Comparison of morphone, oxymorphine and anileridine. Bulletin on Narcotics, Ir, on I, 3-17.

Fraser, H F, Isbell, H, and Van Horn, G D (I957). Effects of morphine as compared with a mixture of morphine and diaminophenylthiazole (daptazole). Anesthesiology, 18, 53 I-535.

Galasko, C S B, and Burn J I (197I). Hypercalcaemia in patients with advanced mammary carcinoma. British Medical fournal, 3, 573-577.

Harte, J D (1975), Personal communication.

Lasagna, L, and Beecher, H K (1954). The optimal dose of morphine. Fournal of the American Medical Association, 156, 230-234.

Lee, L E (1942). Studies of morphine, codeine and their derivatives. XVI fournal of Pharmacology and Experimental Therapeutics, 75, 161-173.

Marks, R M, and Sachar, E J (1973). Undertreatment of medical inpatients with narcotic analgesics. Annals of Internal Medicine, 78, 173-181.

Milton, $\mathrm{G} W$ (1972). The care of the dying. The Medical fournal of Australia, 2, 177-182.

Twycross, R G (1972). The use of diamorphine in the management of terminal cancer. Fournal of Thanatology, 2, 733-743.

Twycross, R G (1974). Clinical experience with diamorphine in advanced malignant disease. International fournal of Clinical Pharmacology, Therapy and Toxicology, 9, 184-198.

World Health Organisation (1964). Expert Committee on Drug Dependence, 13th Report. Technical Report Series no 287.

World Health Organisation (1969). Expert Committee on Drug Dependence, I6th Report. Technical Report Series no 407. 